\title{
Damage control surgery: a constant evolution
}

\section{Cirugía de control de daños: una constante evolución}

\author{
Rao R. Ivatury ${ }^{2}$, David V. Feliciano³, Juan P. Herrera-Escobar ${ }^{4}$ \\ j.herrerae@hotmail.com \\ 1 Virginia Commonwealth University, Department of Surgery, Richmond, VA, USA.2 University \\ of Maryland, Department of Surgery, Baltimore, MD, USA, 3 Harvard Medical School, \\ Department of Surgery, Boston, MA, USA.
}

The story of trauma resuscitation is similar to that of many other advances in medicine: described, forgotten, reinvented, ridiculed, and finally accepted. Even after acceptance, the concepts go through periods of neglect and indifference before they are tried and enhanced, till the next advance.

Damage control, a strategy for management of critically injured or ill patients, is a prime example of this phenomenon. It reminds us of the famous words of Oliver Goldsmith in 1761: "for he who fights and runs away, will live to fight another day, but he who is in battle slain, will never rise and fight again" ${ }^{1}$. Damage control was based on the recognition of the lethal triad of hypothermia, acidosis, and a coagulopathy resulting from massive blood loss, large-volume resuscitation and ischemia-reperfusion. It was an approach that J. Hogarth Pringle ${ }^{2}$ from Glasgow, Scotland, suggested in 1908 with his principles of compression and hepatic packing for control of venous hemorrhage from the injured liver: temporary, expeditious and effective. Packing, however, was rarely utilized during World War II and the Vietnam War because of the presumed risk of rebleeding with removal of the packs. The ever-difficult challenge of "non-surgical bleeding" from a coagulopathy due to massive hepatic injuries did, eventually, lead to a resurrection of the concept of perihepatic packing in the 1980s in civilian centers and became one of the initial steps in damage control for patients with severe and/or multiple intra-abdominal injuries ${ }^{3-6}$.

Corresponding author: Juan P. Herrera-Escobar. Harvard Medical School, Department of Surgery, Boston, MA, USA e-mail: j.herrerae@ hotmail.com

Physiologic exhaustion from massive blood loss leading to intraoperative deaths lead to the concept of an "abbreviated laparotomy" by H. Harlan Stone in $1983^{7}$. Ignored at first, it was subsequently embraced by many trauma centers faced with large numbers of patients with penetrating trauma to the abdomen. The description of this approach with the title of "damage-control" borrowed from the United States Navy by Rotondo et al ${ }^{8}$ popularized the model in the 1990s. Subsequent refinements during the second (ICU) stage of damage control included correction of coagulopathies, suggested end points of resuscitation, earlier recognition of compartment syndromes in the abdomen and extremities, the open-abdomen approach, etc.

Permissive hypotension was the next advance, based on precepts originally described by Cannon and associates in 1918 9: "... inaccessible or uncontrolled sources of blood loss should not be treated with intravenous fluids until the time of surgical control" and, again, in $1923^{10}$ : "Whether blood or an indifferent fluid is injected, careful attention should be given to the mode of the procedure. The possibility of further loss of blood, as the pressure is raised, should be eliminated." These lessons were not relearned till the late 1990s. This is when permissive hypotension, together with changes in blood transfusion (1:1:1 ratio of packed red blood cells: 
fresh frozen plasma: platelet pack), evaluation of deficits in coagulation by thromboelastography or rotational thromboelastometry, and minimization of crystalloid infusion came to be recognized as "Damage Control Resuscitation" ${ }^{11}$ from wartime experience.

The early $21^{\text {st }}$ century witnessed the resurrection of another advance in resuscitation from shock due to non-compressible torso hemorrhage. Originally described by the late Carl W. Hughes $^{12}$, a U.S. Army surgeon in the Korean conflict, balloon occlusion of the aorta, now called resuscitative endovascular balloon occlusion of the aorta (REBOA) was re-discovered by military surgeons in the Iraqi and Afghan wars in 2012 when better equipment became available. The concept has now been re-invigorated by technologic improvements and is enjoying a resurgence for emergency resuscitation in trauma centers. This exciting approach is being defined and refined, very appropriately, in civilian trauma centers in Colombia, long known for having a very high prevalence of penetrating trauma.

Under the leadership of Ricardo Ferrada and Carlos Ordonez, the Hospital Universitario del Valle - Universidad del Valle and lately the Fundación Valle del Lili in Cali are rewriting the principles of resuscitating patients in extremis. During the past decade, Dr. Ordonez and colleagues have published extensively on the subjects of damage control surgery, damage control resuscitation and various aspects of managing trauma in both stable and unstable patients ${ }^{13,14}$. In recent years they have developed a truly multidisciplinary team of surgeons, medical and surgical intensivists, interventional radiologists and other ancillary personnel. They are now recognized as one of the most accomplished trauma centers in their country and the world. They are pioneers in the severe trauma patient management by damage control surgery. Further, they have established national and international collaborations with the support of prestigious surgeons like Juan Carlos Puyana, Michael Aboutanos, and Michael Parra. Additionally, they have contributed to the creation of "Trauma and Acute Care Surgery" fellowship program. They have worked in the education of young trainees from all Latin America including Colombia, Ecuador, Chile, Costa Rica, and Mexico to keep alive the legacy of "damage control" in acute care surgery.

To continue the legacy, the Trauma and Acute Care Surgery group in Cali must continue to strengthen the three pillars of academic surgery (clinical care, education, and research) under two concepts that are becoming essential today: interdisciplinary collaboration and alignment with the "Industry 4.0 ". The complexity of the problems in trauma surgery today requires us to involve other areas of knowledge such as information technology, mechanical engineering, robotics, and even business and government. To solve the main problems in surgery, surgeons cannot be alone in the conversation.

This issue of Surgical Techniques in Damage Control Surgery is a distillation of this experience for the benefit of the rest of Colombia and the world. The contents are thoughtful, welldocumented and compete in their scope. They trace the evolution of the concept of damage control, discuss hybrid operating rooms, and even such provocative ideas as "total body CT scan is efficient and safe in patients with severe trauma and hemodynamic instability" and REBOA use in the penetrating chest trauma management. This contribution will, undoubtedly, be an invaluable asset to all individuals taking care of severely injured patients.

The writers of this editorial have had a long association with surgeons in Colombia as well as the privilege of working in the operating room with them. It is an honor to pen a comment to accompany this "state of the art" report on damage control surgery. 


\section{References}

1. Goodreads. Goldsmith Oliver. Quotes; 2020 Available from: https://www.goodreads.com/author/ quotes/65124.Oliver_Goldsmith. Accessed: 2020 June 4.

2. Pringle JH. V Notes on the arrest of hepatic hemorrhage due to trauma. Ann Surg. 1908; 48(4): 541-9. doi: 10.1097/00000658-190810000-00005

3. Lucas CE, Ledgerwood AM. Prospective evaluation of hemostatic techniques for liver injuries. J Trauma. 1976; 16: 442-51. doi: 10.1097/00005373-197606000-00003.

4. Feliciano DV, Mattox KL, Jordan Jr GL. Intra-abdominal packing for control of hepatic hemorrhage: a reappraisal. J Trauma. 1981; 21: 285-90. DOI: 10.1097/00005373-198104000-00005

5. Feliciano DV, Mattox KL, Burch JM, et al. Packing for control of hepatic hemorrhage. J Trauma. 1986; 26 : 738-43. doi: 10.1097/00005373-198608000-00010.

6. Ivatury RR, Nallathambi M, Gunduz Y, Constable R, Rohman M, Stahl WM. Liver packing for uncontrolled hemorrhage: a reappraisal. J Trauma. 1986; 26: 744-53. doi: 10.1097/00005373-198608000-00011.

7. Stone $\mathrm{HH}$, Strom PR, Mullins RJ. Management of the major coagulopathy with onset during laparotomy. Ann Surg. 1983; 197: 532- 535. doi: 10.1097/00000658-198305000-00005

8. Rotondo MF, Schwab CW, McGonigal M, Phillips GR, Fruchterman T, Kauder D, et al. Damage control: an approach for improved survival in exsanguinating penetrating abdominal injury. J Trauma. 1993; 35: 375-383. DOI:10.1097/00005373-199309000-00008

9. Cannon WB, Faser J, Collew EM. The preventive treatment of wound shock. JAMA. 1918; 70: 618-621.

10. Cannon WB. Traumatic Shock. New York: Appleton; 1923.

11. Holcomb JB, Jenkins D, Rhee P, Mahoney P, Mehta S, Cox ED, et al. Damage control resuscitation: directly addressing the early coagulopathy of trauma. J Trauma. 2007; 62: 307-310. doi: 10.1097/ TA.0b013e3180324124.

12. Hughes CW. Use of an intra-aortic balloon catheter tamponade for controlling intra-abdominal hemorrhage in man. Surgery. 1954; 36: 65-68.

13. Ordonez CA, Rodriguez F, Parra M, Herrera JP, Guzmán-Rodríguez M, Orlas C, et al. Resuscitative endovascular balloon of the aorta is feasible in penetrating chest trauma with major hemorrhage: Proposal of a new institutional deployment algorithm. J Trauma Acute Care Surg. 2020; 89(2):311-319. doi: 10.1097/ TA.0000000000002773.

14. García AF, Manzano-Nunez R, Orlas CP, Ruiz-Yucuma J, Londoño A, Salazar C, et al. Association of resuscitative endovascular balloon occlusion of the aorta (REBOA) and mortality in penetrating trauma patients. Eur J Trauma Emerg Surg. 2020; doi: 10.1007/s00068-020-01370-9. 